\title{
Desain Pembelajaran Gelombang untuk Membentuk Calon Guru Fisika yang Terampil, Berbudaya dan Paham Teknologi Digital
}

\author{
${ }^{1 *}$ Khairil Anwar, ${ }^{2}$ Dadi Rusdiana, ${ }^{3}$ Ida Kaniawati, ${ }^{4}$ Sparisoma Viridi
}

\author{
${ }^{1}$ Program Studi Pendidikan Fisika, FKIP Universitas Muhammadiyah Mataram, Jl. K.H Ahmad \\ Dahlan No.1 Pagesangan Mataram. \\ 2,3Departeman Pendidikan Fisika, Universitas Pendidikan Indonesia, J1. Dr. Setiabudi No. 229, \\ Bandung 40154. \\ ${ }^{4}$ Physics and Biophysis Research Division, Institut Teknologi Bandung, Jl. Ganesha No. 10, Bandung \\ 40132 \\ *Corresponding Author e-mail: khairila593@gmail.com
}

Received: February 2020; Revised: February 2020; Published: March 2020

\begin{abstract}
Abstrak
Tujuan penelitian ini adalah mendesain kegiatan pembelajaran yang berorientasi pada keterampilan kerja ilmiah, pengelolaan alat musik tradisional dan pengelolaan perangkat teknologi digital sebagai sumber belajar melalui matakuliah gelombang, selain itu mengetahui tingkat keterlaksanaan pembelajaran, dan respon mahasiswa terhadap desain kegiatan pembelajaran yang diterapkan. Desain pembelajaran dilakukan dengan cara studi literatur dan studi kasus pada sejumlah kelompok belajar (19 orang mahasiswa) calon guru fisika. Aspek-aspek desain dan keterlaksanaan pembelajaran dievaluasi berdasarkan pengamatan dan respon mahasiswa menggunakan lembar observasi serta kuisioner, sedangkan tanggapan responden dianalisis secara deskriptif berdasarkan rating scale. Orientasi desain pembelajaran gelombang dalam penelitian ini adalah menghubungkan sains dengan teknologi dan masyarakat, mengintegrasikan konten dengan proses penyelidikan ilmiah serta sumber belajar yang kontekstual dengan objek atau peristiwa yang dekat dengan mahasiswa, sekaligus dapat membentuk nilai-nilai budaya. Secara umum setiap aspek dalam desain perkuliahan dapat terlaksana sepenuhnya, dengan rata-rata $98,12 \%$. Sementara itu respon mahasiswa terhadap desain pembelajaran dapat diterima secara positif untuk setiap aspek dari implementasi program pembelajaran dengan skor rata-rata 399,91 (S). Disimpulkan bahwa desain perkuliahan yang dibangun dicirikan oleh sintaks yang meliputi kegiatan awal, eksplorasi, pemfokusan, penyelidikan/inkuiri, elaborasi, konfirmasi, dan kegiatan akhir/penutup, sedangkan sumber belajar melibatkan alat musik tradisional, komputer dan smartphone. Desain pembelajaran dapat mengembangkan kualitas ilmiah mahasiswa calon guru fisika yang diindikasikacn oleh porsentase keterlaksanaan yang mencapai target dan respon positif mahasiswa setelah diterapkannya dalam kegiatan perkuliahan.
\end{abstract}

Kata Kunci: Desain pembelajaran, Alat musik tradisional, Teknologi digital

\section{Design of Wave Learning to Form Prospective Students of Physics Teachers who are Skilled, Cultured and Literacy of Digital Technology}

\begin{abstract}
The purpose of this study is to design learning activities oriented to scientific performance, management of traditional music instruments and digital technology devices as a source of learning on wave courses, knowing the profile of the implementation of learning, and student responses to the design of learning activities that are applied. Learning design is done by means of literature studies and case studies in groups (19 students) prospective physics teachers. The aspects of design and implementation of learning are evaluated based on observations and responses of students using observation sheets and questionnaires, while respondents responses are analyzed descriptively based on rating scale. The orientation of the wave learning design in this research is connecting science with technology and culture, integrating content with scientific inquiry processes and learning resources that are contextual with objects or events that are close to students, as well as forming cultural values. In general, every aspect in the design of lectures can be fully implemented, with an average of $98.12 \%$. Meanwhile student responses to learning designs can be positively received for every aspect of the implementation of learning
\end{abstract}


programs with an average score of 399.91 (S). It was concluded that the learning design that was built was characterized by syntax which included initial activities, exploration, focusing, inquiry, elaboration, confirmation, and closing section activities, while learning resources involved traditional musical instruments, computers and smartphones. The learning design can develop the scientific quality of the prospective physics teacher students as indicated by the percentage of accomplishment that reaches the target and the positive response of students after applying it in lecture activities.

Keywords: Learning design, Traditional music tools, Teknology digital

How to Cite: Anwar, K., Rusdiana, D., Kaniawati, I., \& Viridi, S. (2020). Desain Pembelajaran Gelombang untuk Membentuk Calon Guru Fisika yang Terampil, Berbudaya dan Paham Teknologi Digital. Jurnal Penelitian dan Pengkajian Ilmu Pendidikan: e-Saintika, 4(1), $26-37$. doi:https:// doi.org/10.36312/e-saintika.v4i1.179

https:// doi.org/10.36312/e-saintika.v4i1.179

\section{PENDAHULUAN}

Salah satu tantangan abad 21 dalam dunia pendidikan adalah mempersiapkan guru fisika yang terampil dalam proses sains dan menggunakan teknologi digital untuk mendukung kegiatan pembelajaran (Anwar, Rusdiana, Kaniawati, \& Viridi, 2017; Firdaus, Setiawan, \& Hamidah, 2017; Muhali, 2019). Literasi sains yang mencakup kerja ilmiah dan kemampuan pemecahan masalah calon guru fisika masih rendah (Taufik, Sukmadinata, Abdulhak, \& Tumbelaka, 2010), sebagai contoh kompetensi dan kreativitas guru dalam menyelasaikan masalah atas ketidak tersediaan alat praktikum untuk menggunakan perangkat teknologi digital sebagai alternatifnya (seperti virtual laboratory) masih lemah (Anwar et al., 2017). Salah satu faktor yang membuat lemahnya kecakapan kerja ilmiah guru adalah program persiapan guru belum maksimal mengajarkan penggunaan teknologi (Jona \& Adsit, 2008). Kondisi ini mengindikasikan bahwa proses pembelajaran calon guru fisika di LPTK belum dapat memfasilitasi standar kompetensi kinerja ilmiah dengan baik.

Kemampuan yang harus dimiliki seorang guru fisika di antaranya kemampuan bereksperimen sehingga memerlukan kemampuan berpikir tingkat tinggi, oleh karena itu Wenning merekomendasikan model pembelajaran berbasis praktikum dapat diterapkan untuk mengembangkan daya pikir tingkat tinggi calon guru fisika (Wattimena, Suhandi, \& Setiawan, 2014). Penelitian oleh Wattimena et al., (2014) mengungkapkan selama ini para guru lebih banyak mengenal bentuk kegiatan praktikum melalui diklat atau workshop dan bukan melalui suatu program perkuliahan.

Di sisi konten materi, hasil penelitian menunjukkan bahwa masih banyak mahasiswa yang mengalami miskonsepsi pada konsep panjang gelombang, kecepatan rambat gelombang dan sifat gelombang (Admoko, Yantidewi, \& Oktafia, 2019). Goodhew et al. (2019) dalam makalahnya juga mengungkapkan masih banyak mahasiswa yang memahami kecepatan penjalaran pulsa/kurva gelombang bergantung atau ditentukan oleh bagaimana ia dihasilkan. Hal lain yang masih sulit dialami mahasiswa adalah permasalahan kurva atau grafik yang merepresentasikan suatu fenomena atau peristiwa (Firdaus et al., 2017; Taufik et al., 2010). Sementara itu kegiatan belajar mahasiswa pada matakuliah gelombang didominasi oleh kegiatan mendengarkan penjelasan dosen dengan media slide, buku atau modul yang berisi materi yang berorientasi analitis matematis (Khairil Anwar et al., 2017). Beberapa permasalahan yang disebutkan di atas dapat direduksi melalui pembelajaran model guided discovery dengan memanfaatkan simulasi komputer Lab./Virtual PhET 
(Okimustava, Ishafit, Suwondo, Resmiyanto, \& Praja, 2014) dan model praktikum berbasis outdoor inquiry (Wardani et al., 2019). Wardani et al. (2019) mendesain model praktikum berbasis outdoor inquiry dengan sintaks orientasi masalah, merumuskan hipotesis, pengumpulan data, menguji hipotesis, dan menganalisis data, sehingga model ini dapat meningkatkan keterampilan proses sains secara efektif.

Perkembangan teknologi digital sangat cepat sehingga diperlukan penyesuaian dalam kegiatan pengajaran dan pembelajaran fisika. Mahasiswa calon guru fisika masih jarang mendapat pengalaman belajar gelombang menggunakan komputer atau smartphone sebagai sistem akuisisi data, padahal Petersen (2004) mengatakan bahwa komputer dan smartphone dapat digunakan sebagai bahan pembelajaran fisika. Perangkat komputer dan handphone dapat digunakan untuk membantu memvisualisasikan karakterstik gelombang (Oliver, Underwood, Marotta, Kane, \& Scott, 2013). Komputer juga dapat menyediakan suatu model interaktif atau permodelan gejala fisika (Jona \& Adsit, 2008; Okimustava et al., 2014). Smartphone dapat digunakan untuk mempelajari fenomena gelombang bunyi, membantu untuk menganalisis suara dan mempelajari lebih banyak mengenai karakteristik akustik bunyi (Florea, 2019). Anwar et al., (2016) juga mengungkapkan bahwa pemanfaatan aplikasi smartphone android sebagai media belajar konsep gelombang sangat praktis, efisien, dan efektif. Teknologi dapat menjembatani antara konseptual dengan kehidupan nyata (Firdaus et al., 2017). Dengan demikian komputer dan smartphone sebagai produk teknologi digital dapat difungsikan sebagai sistem akuisisi data karena dapat digunakan untuk mengambil dan mengalisis berbagai jenis data hasil kegiatan peyelidikan suatu fenomena/peristiwa fisis.

Salah satu model pembelajaran fisika yang populer adalah inkuiri (Wenning, 2011; Wenning \& Khan, 2011). Model-model pembelajaran yang berbasis pendekatan ilmiah inkuiri telah banyak dikembangkan, seperti penelitian Taufik et al., (2010) yang mengembangkan model pembelajaran untuk meningkatkan kemampuan pemecahan masalah. Lesson Study dengan tahapannya mengidentifikasi tema penyelidikan, pelaksanaan tema penyelidikan, dan refleksi dapat menjadi model alternatif untuk mengatasi masalah praktik pembelajaran yang kurang efektif (Okimustava et al., 2014). Selain itu Utami et al., (2019) menerapkan model pembelajaran multirepresentasi dalam matakuliah gelombang dan optik berbantuan media slide powerpoint yang mengandung animasi, gambar, dan rumus dimana mahasiswa di stimulus agar dapat merepresentasikan makna-makna rumus ke gambar-gambar animasi tersebut sehingga pembelajaran multirepresentasi efektif untuk meningkatkan pemahaman konsep gelombang. Astuti et al., (2019) mengembangkan program perkuliahan "Flipped Classroom" sebagai cara baru yang menekankan pada pemikiran kritis dengan bantuan teknologi berupa video, audio atau internet pembelajaran, program ini mendapat tanggapan positif dari mahasiswa. Firdaus et al., (2017) merancang model pembelajaran yang bernama MIVA (Model Interface Analisis Video) dengan ciri berbasis teknologi menggunakan video dan perangkat teknolgi komputer interface analisis (LoggePro) pada konsep kinematika. Safaah et al., (2017) merancang pembelajaran menggunakan 5 siklus belajar mulai dari tahap pengamatan, manipulasi, generalisasi, verifikasi, dan aplikasi untuk mengajarkan keterampilan proses sains mahasiswa dan membangun pemahaman konsep mengenai gaya apung.

Berdasarkan permasalahan yang diuraikan di atas yang digambarkan oleh hasil penelitian Taufik et al., (2010) dan Anwar et al., (2017) menunjukkan literasi kerja 
ilmiah dan kemampuan pemecahan masalah calon guru fisika dalam menggunakan perangkat teknologi digital masih lemah. Sementara itu pelatihan penggunaan teknologi untuk pembelajaran fisika belum maksimal (Jona \& Adsit, 2008). Calon guru fisika belum pernah dilatihkan bentuk kegiatan penyelidikan ilmiah melalui suatu program perkuliahan (Wattimena et al., 2014). Lebih lanjut kegiatan belajar materi gelombang masih berpusat pada dosen dengan metode penyampaian materi yang berorientasi pada analitis matematis (Anwar et al., 2017). Sementara itu berbagai desain pembelajaran model penyelidikan ilmiah berbasis inquiry dan pemanfaatan teknologi seperti yang dilakukan oleh Wardani et al. (2019); Okimustava et al., (2014); Petersen (2004); Oliver et al., (2013); Jona (2008); Florea (2019); Firdaus et al., (2017); Wenning \& Khan, (2011); Utami et al., (2019); dan Astuti et al., (2019) belum ada yang menerapkan sumber belajar kontekstual berupa sumber daya lokal seperti alat musik tradisional sebagai bahan belajar getaran, gelombang dan bunyi. Dengan demikian penting dilakukan pengembangan desain pembelajaran gelombang yang berorientasi proses ilmiah dengan mengintegrasikan perangkat teknologi, dan potensi sumber daya lokal untuk mendukung kompetensi calon guru fisika yang sesuai tuntutan zaman sehingga terbentuk keseimbangan pengetahuan teoritis, praktis, keterampilan, serta nilai budaya secara proporsional.

\section{METODE}

Penelitian ini menggunakan jenis penelitian studi kasus dengan pendekatan deskriptif terhadap implementasi program pembelajaran. Subjek penelitian adalah 19 orang mahasiswa calon guru fisika yang terdaftar dalam matakuliah gelombang di salah satu LPTK Kota Mataram-NTB, diambil dengan teknik purposive sampling. Fokus kajian pada penelitian ini adalah karakteristik dan keefektifan dari program pembelajaran gelombang yang berbasis pendekatan ilmiah (scientific approach). Data dikumpulkan menggunakan angket skala likert yang mencakup aspek sikap, motivasi, dan presepsi mahasiswa, serta lembar observasi keterlaksanaan kegiatan pembelajaran yang telah divalidasi oleh 5 orang ahli. Indikator kelayakan program pembelajaran adalah tersusunya sintaks-sintas kegiatan belajar yang melibatkan komponen keterampilan proses sains, kearifan lokal dan teknologi mutakhir, selain itu dapat terlaksananya setiap sintaks secara efektif dan efisien dan minimnya kendala yang dihadapi mahasiswa dalam proses belajar nya, serta terbentuknya sikap positif dan adanya motivasi belajar mahasiswa. Tanggapan responden dianalisis secara deskriptif berdasarkan rating scale kualitatif yang dikonversi menjadi kuantitatif skala likert (1-5) yang bersesuaian dengan pernyataan positif dan negatif dalam kriteria sangat sesuai/sangat setuju/SS (5 untuk pernyataan + dan 1 untuk pernyataan -), setuju/sesuai/S (4 untuk pernyataan + dan 2 untuk pernyataan -), kurang sesuai/kurang setuju/KS (3 untuk pernyataan + dan 3 untuk pernyataan -), tidak sesuai/tidak setuju/TS (2 untuk pernyataan + dan 4 untuk pernyataan -), dan sangat tidak sesuai/sangat tidak setuju/STS (1 untuk pernyataan + dan 5 untuk pernyataan -). Perhitugan scoring untuk setiap jawaban/tanggapan dari masingmasing pernyataan (+ dan -) menggunakan formula "poin $\times \%$ responden" sehingga rating scale setiap kategori dikelompokkan dalam Tabel 1 (Riduwan et al,. 2010 dan Eko, 2012). 
Tabel 1. Klasifikasi Skoring Jawaban pada Setiap Kategori Presepsi.

\begin{tabular}{ccc}
\hline $\begin{array}{c}\text { Skoring kategori } \\
\text { pernyataan }(+)\end{array}$ & Klasifikasi Respons & $\begin{array}{c}\text { Skoring kategori } \\
\text { pernyataan (-) }\end{array}$ \\
\hline $421-500$ & Sangat Setuju/Sesuai (SS). & $100-180$ \\
$341-420$ & Setuju/Sesuai (S). & $181-260$ \\
$261-340$ & Kurang Setuju/Sesuai (KS). & $261-340$ \\
$181-260$ & Tidak Setuju//Sesuai (TS). & $341-420$ \\
$100-180$ & Sangat Tidak Setuju/Sesuai (STS). & $421-500$ \\
\hline
\end{tabular}

Sementara itu aspek keterlaksanaan program (KP) pembelajaran dianalisis secara deskriptif dengan menghitung persentase keterlaksanaan menggunakan formula $\% \mathrm{KP}=$ (Jumlah aspek yang terlaksana/seluruh aspek) $\times 100 \%$ dan dikonsultasikan berdasarkan skor yang diberikan oleh Tabel 2 (Riduwan et al,. 2010 dan Eko, 2012).

Tabel 2. Kriteria Keterlaksanaan Program Perkuliahan.

\begin{tabular}{cl}
\hline Kategori $(\%) \mathrm{KP}$ & Kriteria \\
\hline $\mathrm{KP}=0$ & Tidak ada aspek yang terlaksana \\
$0<\mathrm{KP}<25$ & Sebagian kecil aspek terlaksana \\
$25 \leq \mathrm{KP}<50$ & Hampir separoh aspek terlaksana \\
$\mathrm{KP}=50$ & Separuh aspek terlaksana \\
$50<\mathrm{KP}<75$ & Sebagian besar aspek terlaksana \\
$75 \leq \mathrm{KP}<100$ & Hampir seluruh aspek terlaksana \\
$\mathrm{KP}=100$ & Seluruh aspek terlaksana \\
\hline
\end{tabular}

\section{HASIL DAN PEMBAHASAN}

\section{Desain Kegiatan Pembelajaran Gelombang}

Sintaks pembelajaran didesain berdasarkan studi literatur dengan menganalisis berbagai kondisi belajar, kompetensi, keterampilan, berbagai model, metode, strategi, dan program perkuliahan bagi calon guru fisika, kemudian mensintesis dan menemukan suatu celah yang perlu ditingkatkan/dikembangkan sesuai dengan kebutuhan perkuliahan gelombang yang dapat membentuk calon guru fisika yang terampil, berbudaya dan paham teknologi digital.

Orientasi pembelajaran fisika antara lain mengaplikasikan metode inkuiri saintifik serta memahami hubungan antara sains dengan teknologi dan masyarakat (Okimustava et al., 2014). Investigasi ilmiah yang efektif harus memiliki tujuan pembelajaran yang jelas dan sistem pembelajaran harus mengintegrasikan eksplorasi konten dengan proses melalui penyelidikan ilmiah (Jona \& Adsit, 2008). Model praktikum dalam laboratorium harus dapat membentuk kemampuan berpikir tingkat tinggi peserta didik (Wenning \& Khan, 2011).

Sumber-sumber belajar sedapat mungkin memanfaatkan konten-konten yang bersifat kontekstual terutama berbagai sumber daya yang dekat dengan lingkungan peserta didik agar tercipta pembelajaran yang sesuai dengan keadaan peserta didik (Anwar et al., 2017). Salah satu contoh objek atau peristiwa yang dapat menjadi bahan pembelajaran gelombang yang kontekstual adalah fenomena yang terjadi pada peralatan musik tradisional (Anwar, Rusdiana, Kaniawati, \& Viridi, 2018; Anwar, Viridi, Rusdiana, \& Kaniawati, 2016). Peralatan musik tradisional merupakan sistem yang bergetar yang dapat menunjukkan peristiwa gelombang sehingga dapat memberikan peluang yang tepat untuk membentuk pengetahuan konsep mahasiswa 
melalui objek atau peristiwa yang dekat dengan mahasiswa sekaligus dapat membentuk nilai-nilai budaya (Sari, Anwar, Kurdita, \& Rustaman, 2017).

Desain dan langkah-langkah proses pembelajaran dan pengajaran fisika materi gelombang menggunakan alat musik tradisional dan freeware dalam penelitian ini secara garis besar meliputi: Opening - Exsploration - Focusing - Investigation/Inquiry - Elaboration - Confirmation - Closing.

Kegiatan Awal

1. Video Peralatan musik tradisional.

2. Tujuan dan indikator belajar.

3. Pengelompokkan

Sebagai kegiatan pembuka dilakukan "pengorganisasian". Mahasiswa disuguhkan dengan beberapa video alat musik dan permainan musik yang menggunakan alat musik tradisional yang sumber getarnya dawai, kolom udara, pelat, dan membran, serta menampilkan beberapa software dan aplikasi pendukung untuk merangsang seluruh indra dan memunculkan rasa ingin tahu mahasiswa. Berikutnya dosen menyampaikan tujuan dan indikator pencapaian belajar dan membentuk kelompok kecil yang terdiri dari 3-4 anggota.

\section{Eksplorasi}

\section{Apresiasi dan motivasi}

2. Demonstrasi interaktif,

3. Eksplorasi berbagai konsep dan Hubungannya.

Menerapkan model "level of inquiry" (Wenning, 2011; Wenning \& Khan, 2011). Pada tahap discovery learning, dosen memunculkan suatu permasalahan dan mahasiswa mencoba menyelesaikannya dengan bantuan pertanyaan produktif, mengenalkan istilah-istilah besaran fisis yang terkait. Melalui Interactive Demonstration mahasiswa melakukan identifikasi, prediksi, dan menjelaskan konsepkonsep dasar, dosen membantu mahasiswa mengidentifikasi jenis-jenis variabel. Mahasiswa mengeksplorasi tentang berbagai konsep dan keterkaitan satu sama lain yang dapat dipelajari melalui alat musik tradisional.

Fokus

1. Menyeleksi tema esensial.

2. Alat musik tradisional dan LKM.

3. Alat dan Bahan, serta perangkat komputer atau smartphone.

Dalam tahap ini, dosen mensortir tema-tema penyelidikan yang muncul dari ide-ide mahasiwa untuk membatasi konsep-konsep esensial, selanjutnya membagikan alat musik tradisional dan LKM pada setiap kelompok sesuai dengan tema yang akan diselidiki. Dalam satu hubungan konsep, setiap kelompok hanya difokuskan untuk menyelidiki satu sub konsep saja.

Penyelidikan

1. Penyelidikan objek alat musik tradisional berdasarkan panduan LKM.

2. Menggunakan berbagai perangkat digital (komputer dan Smartphone)

3. Pembimbingan dengan pertanyaan produktif,

Setiap proses penyelidikan dipandu dengan LKM. Tahap ini merupakan aktivitas inkuiri lab. dimana mahasiswa menyelidiki fenomena gelombang untuk menemukan suatu konsep atau bagian hubungan konsep. Keterampilan yang 
dilatihakan mulai dari merumuskan masalah, hipotesis, mendefinisikan variabel, merancang percobaan, merancang tabel, mengumpulkan data, membangun grafik, menganalisis data hingga mengumpulkan temuan-temuan.

Elaborasi

\section{Laporan singkat/sederhana.}

2. Presentasi temuan.

3. Diskusi

Tahap elaborasi merupakan tahap untuk menginformasikan, mengkoordinasi, dan mendiskusikan masing-masing temuan hasil penyelidikan. Setiap kelompok melakukan presentasi singkat hasil temuan sedangkan kelompok lain menanggapi dan mengkordinasi.

Konfirmasi

1. Penguatan konsep secara teoritis.

2. Verifikasi hasil penyelidikan.

Pada tahap konfirmasi, dosen memberikan penguatan konsep dan prinsip secara teoritis, dan mahasiswa memverifikasi masing-masing hasil penyelidikannya. Assesmen dan Evaluasi

1. Penilaian (kualitatif).

2. Wawancara.

3. Refleksi dan Tindak lanjut.

Dosen melakukan penilaian kinerja mahasiswa secara kualitatif, melakukan wawancara singkat untuk mengkonfirmasi pengetahuan atau keterampilan yang diperoleh. Hasil penilaian dijadikan sebagai bahan refleksi bagi mahasiswa untuk tindakan lanjut perbaikan laporan hasil penyelidikan.

$$
\text { Penutup }
$$

1. Penyimpulan.

2. Informasi materi lanjutan.

3. Penjadwalan penyerahan laporan kegiatan.

4. Mengakhiri perkuliahan.

Pada tahap akhir kegiatan pembelajaran, dosen dan mahasiswa membuat kesimpulan secara general dan melakukan refleksi terhadap proses pembelajaran dan pengajaran yang telah dilakukan untuk memperbaiki kegiatan pembelajaran berikutnya. Dosen memberikan informasi materi yang akan dipelajari pada pertemuan berikutnya serta mengingatkan/menetapkan jadwal penyerahan laporan LKM yang telah diperbaiki.

Kegiatan pembelajaran kelas yang telah didesain dalam makalah ini mampu menjadi alternatif aktivitas laboratorium serta mengubah pandangan dan motivasi belajar mahasiswa calon guru fisika, sebagaimana diungkapkan oleh (Anwar, Rusdiana, Kaniawati, \& Viridi, 2018; Anwar, Rusdiana, et al., 2016; Okimustava et al., 2014; Sari et al., 2017) bahwa pengalaman laborartorium dapat mengembangkan pemahaman konsep dan keterampilan saintifik mahasiswa. Sejalan dengan ini (Firdaus et al., 2017) mengatakan bahwa metode demonstrasi dan eksperimen dapat menjadi strategi yang tepat untuk mengatasi masalah literasi grafik pada mahasiswa. Lebih lanjut (Okimustava et al., 2014) mencontohkan pemanfaatan perangkat teknologi simulasi (SBL) dan PhET serta VBL dan Tracker untuk mempelajari topik 
efek foto listrik, watak lampu pijar, momentum dan getaran harmonik melalui matakuliah eksperimen fisika.

\section{Keterlaksanaan Pembelajaran}

Keterlaksanaan kegiatan pengajaran dan pembelajaran yang di desain dapat ditunjukkan dari beberapa indikator yang dirangkum dalam Tabel 3.

Tabel 3. Rekapitulias Keterlaksanaan Kegiatan Pembelajaran Gelombang.

\begin{tabular}{clc}
\hline No. & \multicolumn{1}{c}{ Indikator Keterlaksanaan Program } & Skor $(\%)$ \\
\hline 1. & Terjadi stimulus dan orientasi awal serta antusiasme mahasiswa. & 100 \\
2. & $\begin{array}{l}\text { Terjadi apresiasi dan interaksi positif antara dosen dan } \\
\text { mahasiswa. }\end{array}$ & 90 \\
3. & $\begin{array}{l}\text { Terbentuk aktivitas identifikasi berbagai ide dan gagasan konsep } \\
\text { esensial fenomena getaran, gelombang dan bunyi. }\end{array}$ & 100 \\
4. & $\begin{array}{l}\text { Setiap media dan fasilitas sumber belajar dapat beroperasi dengan } \\
\text { baik. }\end{array}$ & 100 \\
5. & $\begin{array}{l}\text { Setiap kelompok aktif melakukan kegiatan penyelidikan. } \\
\text { 6. }\end{array}$ & $\begin{array}{l}\text { Kegiatan pada setiap tema penyelidikan terselesaikan hingga } \\
\text { menemukan hasil. }\end{array}$ \\
7. & Terjadi aktivitas presentasi dan diskusi & 100 \\
8. & Adanya aktivitas verifikasi dan penguatan konsep. & 100 \\
\hline
\end{tabular}

Setiap pertemuan, seluruh aktivitas dosen dan mahasiswa dilakukan observasi berdasarkan aspek-aspek dan komponen yang telah dirancang dalam RPP. Pengamatan dilakukan oleh 2 orang observer (Dosen dan asistensi) setiap pertemuan kelas. Catatan-catatan yang diberikan oleh observer digunakan sebagai bahan refleksi untuk perbaikan dan peningkatan desain aktivitas pembelajaran.

Secara umum setiap aspek dalam desain perkuliahan dapat dilaksanakan. Proses perkuliahan dilihat dari aktivitas dosen dan mahasiswa dapat dikatakan terlaksana dengan baik dengan rata-rata 98,125 \% karena sebagian besar aspek kegiatan dapat terpenuhi. Sementara itu pada tahap pemberian apresiasi awal masih terlihat kurangnya interaksi timbal balik mahasiswa terhadap pertanyaan-pertanyaan diskusi pada berbagai pertemuan, hal ini disebabkan karena keterampilan berkomunikasi mahasiswa masih minim dan terlihat kurang percaya diri dalam mengungkapkan pandangannya, selain itu pengetahuan awal mahasiswa akan konsep dasar getaran gelombang terlihat masih sangat rendah, terlebih pada peristiwa dalam objek alat musik tradisional, hal ini sejalan dengan hasil penelitian (Anwar et al., 2017).

Pada pertemuan pertama, mahasiswa belum dapat mengajukan pandangan/gagasan terhadap fenomena yang ditunjukkan meskipun sangat antusias menyimak dan memperhatikan fenomena yang terjadi. Respon akan identifikasi variabel masih minim karena mahasiswa masih belum memahami makna variabel dalam proses sains dan masih dalam tahap adaptasi dengan pendekatan pembelajaran yang diterapan, sementara itu kemampuan berfikir kritis mahasiswa belum terbentuk. Solusi untuk mengatasi masalah ini adalah memberikan porsi yang lebih banyak pada kegiatan discovery learning dan demonstrasi interaktif untuk memperkenalkan istilah-istilah dan peristiwa.

Meskipun setiap kelompok terlihat aktif melakukan kegiatan penyelidikan membangun konsep, namun beberapa proses masih harus terkontrol oleh dosen 
karena masih banyak kelompok mahasiswa yang menemukan kesulitan terutama dalam mendesain peyelidikan dan pengoperasian perangkat teknologi, termasuk proses analisis data hingga merepresentasikannya secara grafis. Literasi grafik mahasiswa masih sangat rendah, hal ini sejalan dengan hasil penelitian yang diungkapkan oleh (Dewi, Putra, \& Susilo, 2018; Dimas, Suparmi, Sarwanto, \& Nugraha, 2018; Klein, Küchemann, Brückner, Zlatkin-Troitschanskaia, \& Kuhn, 2019). Pada tahap ini, pengelolaan waktu juga menjadi bagian fokus refleksi karena banyak digunakan untuk kegiatan inkuiri laboratorium, sehingga solusi yang perlu dilakukan adalah memberikan pelatihan awal sebagai pertemuan pendahuluan dalam pengelolaan perangkat teknologi, grafis dan latihan inkuiri, menimbang komponen dan unsur-unsur dalam program perkuliahan ini merupakan pengalaman baru bagi mahasiswa.

Pada tahap presentasi dan diskusi meski setiap kelompok dapat melakukan presentasi namun masih terlihat belum meratanya aktivitas diskusi di antara mahasiawa karena masih terlihat adanya dominasi kelompok yang aktif dalam memberikan tanggapan dan pertanyaan.

\section{Respons Mahasiswa terhadap Desain Pembelajaran.}

Rekapitulasi respon mahasiswa terhadap desain pembelajaran yang dilakukan dengan model inkuiri melalui alat musik tradisional dan perangkat teknologi ditunjukkan dalam Gambar 1.

Skor \& Kategori Presepsi Mahasiswa terhadap Implementasi Desain Pembelajaran Gelombang

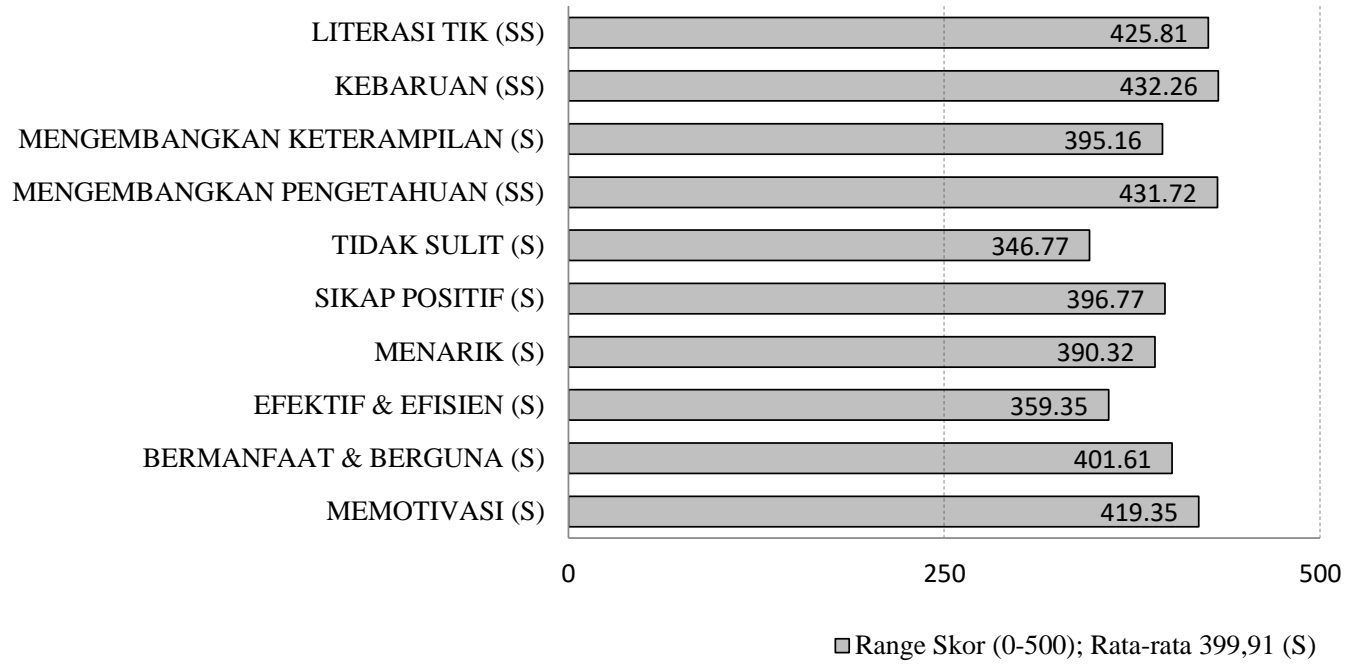

Gambar 1. Rekapitulias Tanggapan Mahasiswa terhadap Desain Pembelajaran Gelombang.

Mayoritas respon mahasiswa terhadap desain pembelajaran yang diterapkan dapat diterima secara positif dengan skor rata-rata 399,91 yang berarti menyetujui (S) setiap aspek dari implementasi program pembelajaran. Pembelajaran fisika yang dikaitkan dengan instrumen musik tradisional dapat meningkatkan motivasi dan ketertarikan mahasiswa dalam pembelajaran konsep gelombang karena selain memberikan manfaat pengetahuan sains juga dapat memberikan informasi fisis dan matematis terkait karakteristik alat musik tradisional serta dapat melestarikan budaya 
(seni musik) tradisional yang saat ini mulai pudar eksistensinya di kalangan generasi milenial.

Selain pengetahuan, mahasiswa pun memberikan pandangannya bahwa desain program pembelajaran dapat mengembangkan keterampilan proses sains, dapat melatih sikap mahasiswa dalam bekerjasama, toleransi, dan tanggung jawab dan dapat melatihkan kemampuan berkomunikasi lisan melalui kegiatan diskusi kelas. Hal lain yang sangat inovatif adalah dapat memberikan wawasan dan pengalaman pemanfaatan perangkat TIK sebagai media pembelajaran fisika yang efisien, praktis, efektif dan inovatif yang sesuai dengan keadaan dan harapan mahasiswa saat ini dan prospek dunia pendidikan di masa depan.

Sebagian besar mahasiswa memberikan tanggapan bahwa proses perkuliahan relatif mudah untuk dilaksanakan, hal ini dapat juga di lihat dari keterlaksanaannya seluruh kegiatan belajar dalam membangun konsep hingga dapat melakukan kegiatan diskusi kelas dan dengan pendampingan dan pembimbingan dosen.

Meskipun berbagai respon positif diberikan oleh mahasiswa, namun respon negatif yang menjadi masukan konstruktif juga dinyatakan oleh mahasiswa dimana desain pembelajaran memerlukan waktu kegiatan belajar yang cukup lama, materi ajar yang disajikan hanya berupa konsep-konsep dasar saja, membutuhkan media alat musik yang representatif sesuai dengan jumlah mahasiswa dan membutuhkan tambahan biaya untuk keperluan pengadaan alat dan bahan belajar serta kurang efektif jika diterapkan pada lingkungan belajar yang minim fasilitas TIK.

Berdasarkan berbagai hasil dan pembahasan penelitian di atas maka desain dan metode pembelajaran ini perlu ditingkatkan dan dikembangkan secara kontinyu terutama menghubungkannya dengan instrumen musik tradisional lainya yang ada si seluruh Indonesia, sebagaimana Anggraeni et al., (2019) merancang pembelajaran gelombang bunyi menggunakan gamelan dan smarphone yang juga mendapat tanggapan baik dari para siswa dimana dapat membangkitkan antusiasme dan rasa ingin tahu, siswa dapat mengenal berbagai macam instrumen gamelan dan cara memainkannya serta siswa dapat melihat bentuk gelombang bunyi gamelan secara langsung dan real time.

\section{KESIMPULAN}

Sesuai dengan hasil dan diskusi, dapat disimpulkan bahwa desain pembelajaran mata kuliah gelombang memiliki karateristik penerapan sumber belajar kontekstual dengan melibatkan sumber daya lokal dan perangkat teknologi digital (komputer dan smartphone) yang berbasis aktivitas inkuiri terbimbing dengan lembar kerja mahasiswa yang berorientasi proses sains. Sintaks dalam desain permbelajaran meliputi Opening - Exsploration - Focusing - Investigation/Inquiry - Elaboration Confirmation - Closing. Desain pembelajaran dapat dilaksanakan dengan baik melalui aktivitas kelas sesuai dengan situasi, kondisi dan waktu yang tersedia, serta mendapat tanggapan positif dari mayoritas mahasiswa dengan beberapa masukan dan refleksi untuk pengembangan lebih lanjut.

\section{SARAN}

Perlu dilakukan pengukuran pengaruh implementasi desain pembelajaran terhadap hasil belajar dan keterampilan proses sains mahasiswa melalui instrumen tes penguasaan konsep dan keterampilan proses sains. 


\section{UCAPAN TERIMA KASIH}

Terimakasih ditujukan kepada Universitas Muhammadiyah Mataram atas dukungan dana penelitian.

\section{DAFTAR PUSTAKA}

Admoko, S., Yantidewi, M., \& Oktafia, R. (2019). The Implementation of Guided Discovery Learning Using Virtual Lab Simulation To Reduce Students' Misconception on Mechanical Wave. Journal of Physics: Conference Series, 1417, 012089. https:/ / doi.org/10.1088/1742-6596/1417/1/012089

Anggraeni, D. P., Sukarmin, \& Nurosyid, F. (2019). Teaching sound waves using gamelan and smartphones. Journal of Physics: Conference Series, 1153(1). https:/ / doi.org/10.1088/1742-6596/1153/1/012123

Anwar, K., Rusdiana, D., Kaniawati, I., \& Viridi, S. (2018). Construction of basic concepts of waves through a "gambo" (traditional musical instrument). AIP Conference Proceedings, 2021. https:/ / doi.org/10.1063/1.5062747

Anwar, K., Rusdiana, D., Kaniawati, I., \& Viridi, S. (2016). Pemanfaatan Applikasi Smartphone Android sebagai Media Belajar Fisika. Seminar Nasional Quantum, (229), 71-82.

Anwar, K., Rusdiana, D., Kaniawati, I., \& Viridi, S. (2017). Profil Pembelajaran dan Pengajaran Fisika (Getaran-Gelombang) yang Sesuai Abad 21. Paedagoria, 8(2), $16-23$.

Anwar, K., Rusdiana, D., Kaniawati, I., \& Viridi, S. (2018). Construction of basic concepts of waves through a "gambo" (traditional musical instrument). AIP Conference Proceedings, 2021. https:/ / doi.org/10.1063/1.5062747

Anwar, K., Viridi, S., Rusdiana, D., \& Kaniawati, I. (2016). PROSIDING SNIPS 2016 Telaah Alat Musik Tradisional Etnik Mbojo sebagai Media Pembelajaran Fisika. 481490.

Astuti, I. A. D., Bhakti, Y. B., Sumarni, R. A., Sulisworo, D., \& Toifur, M. (2019). Flipped Classroom As a Millenial Teaching Model. Indonesian Review of Physics, 2(1), 22. https:/ / doi.org/10.12928/irip.v2i1.811

Dewi, A. R. C., Putra, N. M. D., \& Susilo. (2018). Analysis of graphic representation ability in oscillation phenomena. Journal of Physics: Conference Series, 983(1). https:/ / doi.org/10.1088/1742-6596/983/1/012024

Dimas, A., Suparmi, A., Sarwanto, S., \& Nugraha, D. A. (2018). Analysis multiple representation skills of high school students on simple harmonic motion. AIP Conference Proceedings, 2014(September). https://doi.org/10.1063/1.5054535

Eko, P. W. S., (2012). Teknik Penyusunan Instrumen Penelitian. Pustaka Pelajar: Yogyakarta.

Firdaus, T., Setiawan, W., \& Hamidah, I. (2017). The Kinematic Learning Model using Video and Interfaces Analysis. Journal of Physics: Conference Series, 895(1). https:/ / doi.org/10.1088/1742-6596/895/1/012108

Florea, C. (2019). Brief Analysis of Sounds Using a Smartphone. The Physics Teacher, 57(4), 214-215. https:// doi.org/10.1119/1.5095371

Goodhew, L. M., Robertson, A. D., Heron, P. R. L., \& Scherr, R. E. (2019). Student conceptual resources for understanding mechanical wave propagation. Physical $\begin{array}{llll}\text { Review Physics Education Research, } 20127 . & \text { 15(2), }\end{array}$ https:/ / doi.org/10.1103/PhysRevPhysEducRes.15.020127

Jona, K., \& Adsit, J. (2008). Goals, guidelines, and standards for student scientific 
investigations. North American Council for Online Learning, (June). Retrieved from http://www.inacol.org/

Klein, P., Küchemann, S., Brückner, S., Zlatkin-Troitschanskaia, O., \& Kuhn, J. (2019). Student understanding of graph slope and area under a curve: A replication study comparing first-year physics and economics students. Physical Review Physics Education Research, 15(2), 20116. https:/ / doi.org/10.1103/PhysRevPhysEducRes.15.020116

Muhali, M. (2019). Pembelajaran Inovatif Abad Ke-21. Jurnal Penelitian Dan Pengkajian Ilmu Pendidikan: E-Saintika, 3(2), 25-50. https://doi.org/10.36312/esaintika.v3i2.126

Okimustava, O., Ishafit, I., Suwondo, N., Resmiyanto, R., \& Praja, A. R. I. (2014). Pengembangan Kuliah Eksperimen Fisika dengan Teknologi Multimedia. Jurnal Riset Dan Kajian Pendidikan Fisika, 1(1), 1. https:/ / doi.org/10.12928/jrkpf.v1i1.1516

Oliver, D., Underwood, J., Marotta, D., Kane, J., \& Scott, M. (2013). Four Free Software Packages Related to the Physics of Sound. The Physics Teacher, 51(2), 101-104. https:/ / doi.org/10.1119/1.4775532

Petersen, M. R. (2004). Musical Analysis and Synthesis in Matlab. The College Mathematics Journal, 35(5), 396. https:/ / doi.org/10.2307/4146853

Riduwan dan Sunarto. (2010). Pengantar Statistika. Bandung: Alfabeta.

Safaah, E. S., Muslim, M., \& Liliawati, W. (2017). Teaching Science Process Skills by Using the 5-Stage Learning Cycle in Junior High School. Journal of Physics: Conference Series, 895(1). https:/ / doi.org/10.1088/1742-6596/895/1/012106

Sari, I. M., Anwar, K., Kurdita, E., \& Rustaman, N. (2017). Sundanese flute: from Art and Physics perspective. 57(ICMSEd 2016), 221-225. https://doi.org/10.2991/icmsed16.2017.48

Taufik, M., Sukmadinata, N. S., Abdulhak, I., \& Tumbelaka, B. Y. (2010). Desain Model Pembelajaran Untuk Meningkatkan Kemampuan Pemecahan Masalah Dalam Pembelajaran IPA (Fisika) Sekolah Menengah Pertama Di Kota Bandung. Berkala Fisika, 13(2), 31-44.

Utami, L. S., Wayan, N., \& Darmayanti, S. (2019). Pemahaman konsep mahasiswa fisika materi gelombang dan optik tahun akademik 2018/2019. 5, 53-58.

Wardani, Y. R., Mundilarto, M., Jumadi, J., Wilujeng, I., Kuswanto, H., \& Astuti, D. P. (2019). The Influence of Practicum-Based Outdoor Inquiry Model on Science Process Skills in Learning Physics. Jurnal Ilmiah Pendidikan Fisika Al-Biruni, 8(1), 23-33. https:// doi.org/10.24042/jipfalbiruni.v8i1.3647

Wattimena, H., Suhandi, A., \& Setiawan, A. (2014). Profil Penyelenggaraan Praktikum Fisika Sekolah Sebagai Penyiapan Mengembangkan Kreativitas Calon Guru. Jurnal Pendidikan MIPA Universitas Lampung, 15(2).

Wenning, C. J. (2011). Level of Inquiry: Using Inquiry Spectrum Learning Sequences on Teach Science. Journal of Physics Teacher Eucation Online, 6(2), 11-20.

Wenning, C. J., \& Khan, M. A. (2011). Levels of Inquiry Model of Science Teaching: Learning sequences to lesson plans. Journal of Physics Teacher Education Online, 6(2), 17-20. 